\title{
Raising awareness of the needs of older COVID patients after hospital discharge
}

\author{
Jean-Pierre Michel ${ }^{1} \cdot$ Stefania Maggi ${ }^{2} \cdot$ Fiona Ecarnot $^{3,4} \mathbb{C}$
}

Received: 5 May 2020 / Accepted: 3 June 2020 / Published online: 12 June 2020

(c) Springer Nature Switzerland AG 2020

\section{Introduction}

Ten years ago, a task force of the Society of Critical Care Medicine (SCCM) examined the onset or worsening of mental health, physical, and cognitive outcomes arising after critical illness, and coined the term "Post Intensive Care Syndrome" (PICS) to describe the phenomenon [1]. The concept was subsequently broadened to encompass the mental health status of the patient's family (PICS-F) [2].

Before the pandemic of coronavirus disease (COVID-19) caused by the severe acute respiratory syndrome coronavirus-2 (SARS-CoV-2), approximately 19 million individuals per year developed life-threatening acute organ dysfunction secondary to sepsis necessitating admission to the intensive care unit (ICU). Among these, 14 million survive, half of these survivors recover, one third die during the year following ICU discharge, and one sixth experience permanent functional disability $[3,4]$, requiring partial or total help with the activities of daily living [5].

There is a paucity of literature devoted to the problem of PICS after COVID-19 [6-8], and no data on PICS in older survivors of severe COVID-19. Yet, to date, worldwide, more than 3 million people have been infected with COVID-19, of whom approximately $3 \%$ will require intensive care and mechanical ventilation. The length of stay in ICU and the duration of ventilator reliance are considerably longer in COVID-19, at up to 3 weeks, than in more typical ICU populations [9]. Every day, the media update the death toll, which has already exceeded 400,000 and continues to

\footnotetext{
Fiona Ecarnot

Fiona.ecarnot@Univ-fcomte.fr

Medical University of Geneva, Geneva, Switzerland

2 National Research Council, Neuroscience Institute, Padua, Italy

3 Department of Cardiology, University Hospital Besancon, Boulevard Fleming, 25000 Besancon, France

4 EA3920, University of Franche-Comté, Besancon, France
}

rise. Among patients requiring admission to the ICU, almost all need respiratory support, and $88 \%$ require mechanical ventilation [10]. Although roughly one-third of infected patients are over 60 years of age, more than two-thirds of deaths occur in this age group [11]. Old patients recovering from severe respiratory illness present secondary disability resulting from intensive treatments. This includes (but is not limited to) acute unit-acquired weakness, long-term cognitive impairment, and poor mental outcomes $[4,5,12]$, while the patient's family members, especially the older ones, will suffer a high psychological burden [13, 14].

Geriatricians need to be aware of these alarming data. Indeed, the COVID-19 pandemic will soon reveal the public health burden of PICS among survivors of intensive care and mechanical ventilation. There are numerous studies and reviews devoted to the management of acute COVID-19 and its immediate sequelae [12,15-17]. We focus here on the involvement of multidisciplinary geriatric teams to prevent physical, cognitive and mental repercussions of COVID-19 treatment in older survivors who are discharged alive from the ICU. Geriatricians also need to anticipate the sociopsychological and economic impacts on the patient's whole family.

\section{Current knowledge on the long-term outcomes of PICS}

The symptoms of PICS are well established, and include fatigue, muscle weakness, difficulty swallowing, cloudy thinking, difficulty concentrating, poor memory, anxiety, sadness and sleep disturbances [3, 4].

Among the physical outcomes is intensive unit-acquired muscle weakness, which results from microvascular ischemia or injury, immobility, catabolism and dysfunction of the sodium channels and mitochondria [16]. About $40 \%$ of patients suffer from polyneuropathy, neuromyopathy, or myopathy, which can result in muscle deconditioning [16]. Three months after discharge from the ICU after critical 
sepsis, about half of older survivors have functional recovery, and older survivors of sepsis develop 1.5 new limitations in the activities of daily living compared to 0.5 limitations in their non-ICU counterparts [13]. This may explain the greater need for community services, or the higher rates of institutionalization for rehabilitation or nursing care observed after discharge in this age group [3, 4]. Indeed, such poor physical outcomes could be aggravated by the pre-ICU health, body mass, and visual or hearing conditions.

After an ICU stay, the main cognitive impairments that persist long term are executive dysfunction, as well as memory and attention disturbances, rather than pure memory alteration. The multi-domain cognitive impairments appear to be linked to hypo- or hyperglycaemia, delirium and in-hospital acute stress [16]. The lesions observed in long-term post-ICU cognitive impairment seem to be different from those seen in Alzheimer's disease, with smaller superior frontal lobe, thalamus and cerebellar volume associated with white matter damage [13]. In a random sample of 10,348 subjects who received intensive care and survived to discharge, during 3 years of follow-up, the incidence of newly diagnosed dementia was $15 \%$ in ICU survivors, versus $12.2 \%$ in matched controls [18]. The long-term cognitive outcomes of ICU survivors depend also on the prevalence of pre-morbid disorders and ICU-related stress. Female sex, lower education level, anxiety, pre-existing depression or post-traumatic stress disorder and alcohol abuse may all increase the risk of ICU-acquired mental illness [19]. Among adult ICU survivors, the prevalence is $19-37 \%$ for depression, $32-40 \%$ for anxiety and $19-22 \%$ for post-traumatic stress [13, 19-21]. Anxiety, depression and sleep disorders can last months to years, while post-traumatic stress disorder can persist for up to 8 years [5].

\section{Current knowledge on the long-term outcomes of PICS-family}

Family members of critically ill patients experience stress, anxiety, depression and complicated grief [22]. Demographic factors favoring these disorders include female gender, younger age of the patient, lower education level, being the patient's spouse, a previous history or family history of mental health disorders [13]. There is a close relation between these predisposing factors, and ICU-related determinants, such as a perception of the patient being very near death, unexpected or sudden patient illness, family members with greater levels of anxiety and depression about the ICU hospitalization, and poor communication between family members and ICU physicians [13]. All these conditions combine to explain the rate of depression among family members of critically ill patients, which varies from 14.6 to $66.6 \%$ in the first ICU week, and may remain as high as $17.9 \%$ after 6 months. In parallel, anxiety affects between 42 and $66.6 \%$ in the first ICU week, and may persist in $15-24 \%$ at 6 months, comparable to the 6-month prevalence of posttraumatic stress disorder (33.1-49\%) [16].

These long-term impairments stemming from ICU admission can cause survivors to have poor quality of life, while their families and the healthcare system, in general, also face numerous challenges that no "silver bullet" can resolve [12].

\section{Intervention by a multidisciplinary geriatric team may help reduce PICS and PICS-F}

The ABCDEF bundle is a well-established, multicomponent, evidence-based guide for coordinating multidisciplinary ICU care, and optimizing patient recovery and outcomes. The ABCDEF bundle includes (1) assess, prevent, manage pain; (2) both spontaneous awakening and spontaneous breathing trials; (3) choice of analgesia and sedation; (4) delirium: assess, prevent, manage; (5) early mobility and exercise; and (6) Family engagement and empowerment [23, 24]. The development of person-centered intensive care was fueled by the importance of understanding "what matters most" to individuals [15], for both short- and long-term care. In emergency cases, especially in the case of pandemics, regardless of how compassionate the health professionals may be, they are often called upon to initiate treatments and make decisions without knowledge of the patient's personal background, wishes or values, and sometimes without being able to consult a family member or surrogate. This may result in care processes that are not aligned with the patient's desires. Thus, continued efforts have been made to consolidate the importance of the F element (family engagement and empowerment, follow-up referrals, and functional reconciliation), and to add two new important letters to the classical bundle, namely $(\mathrm{G})$ for good handoff communication and $(\mathrm{H})$ for handout materials on PICS and PICS-F [16].

The early phase of recovery after discharge depends on the quality of the transfer instructions, the information provided to healthcare professionals, medication reconciliation, continuation of nutritional and rehabilitative processes and psychological support [12]. Performing comprehensive geriatric assessment at the time of transfer from the ICU to a geriatric ward (or other structure) is essential to better target and coordinate appropriate multidisciplinary team interventions. These interventions should aim to evaluate the patient's treatable conditions (e.g., infection, heart failure, renal failure), identify any new physical, cognitive and mental disturbances, review and adjust medication, and set dates for careful follow-up [3]. Moreover, results of this assessment would help to give the family members more accurate prognostic information, and to offer them regular updates. If the results indicated that assistance was required, social workers and, where necessary, psychologists or psychiatrists 
could be contacted to provide support. The family's perception of the quality of care received by their loved one, their confidence in open communication, and their access to resources to help reduce the care-related and social burden are key contributors to reducing the psychological impact of PICS [14].

In summary, geriatric teams need to be aware of PICS in older patients who survive critical illness and a stay in the ICU, and of their responsibility towards the patient beyond saving their lives [25]. Consequently, geriatric teams can adapt health services and coordinate the different care actors to provide the most appropriate home or institutional care, with a view to reducing the impact on both patient and family in the post-ICU period. In the context of the current pandemic of COVID-19, we must be alert not only to the imminent danger that infection represents for older subjects, but also to the long-term threat to quality of life and daily functioning posed by PICS.

Funding No funding was received for this work.

\section{Compliance with ethical standards}

Conflict of interest The authors have no conflict of Interest and no funding to declare.

Statement of human and animal rights Not applicable.

Informed consent Not applicable.

\section{References}

1. Needham DM, Davidson J, Cohen $\mathrm{H}$ et al (2012) Improving longterm outcomes after discharge from intensive care unit: report from a stakeholders' conference. Crit Care Med 40:502-509. https ://doi.org/10.1097/CCM.0b013e318232da75

2. Elliott D, Davidson JE, Harvey MA et al (2014) Exploring the scope of post-intensive care syndrome therapy and care: engagement of non-critical care providers and survivors in a second stakeholders meeting. Crit Care Med 42:2518-2526. https://doi. org/10.1097/CCM.0000000000000525

3. Prescott HC, Angus DC (2018) Enhancing recovery from sepsis: a review. JAMA 319:62-75. https://doi.org/10.1001/ jama.2017.17687

4. Dos Santos C, Hussain SN, Mathur S et al (2016) Mechanisms of chronic muscle wasting and dysfunction after an intensive care unit stay. A pilot study. Am J Respir Crit Care Med 194:821-830. https://doi.org/10.1164/rccm.201512-2344OC

5. Davidson JE, Harvey MA (2016) Patient and family post-intensive care syndrome. AACN Adv Crit Care 27:184-186. https://doi. org/10.4037/aacnacc2016132

6. Nikolich-Zugich J, Knox KS, Rios CT et al (2020) SARS-CoV-2 and COVID-19 in older adults: what we may expect regarding pathogenesis, immune responses, and outcomes. Geroscience. https://doi.org/10.1007/s11357-020-00186-0
7. Stam HJ, Stucki G, Bickenbach J (2020) Covid-19 and post intensive care syndrome: a call for action. J Rehabil Med 52:jrm00044. https://doi.org/10.2340/16501977-2677

8. Alhazzani W, Moller MH, Arabi YM et al (2020) Surviving sepsis campaign: guidelines on the management of critically ill adults with coronavirus disease 2019 (COVID-19). Intensive Care Med. https://doi.org/10.1007/s00134-020-06022-5

9. Choon-Huat Koh G, Hoenig H (2020) How should the rehabilitation community prepare for 2019-nCoV? Arch Phys Med Rehabil. https://doi.org/10.1016/j.apmr.2020.03.003

10. Grasselli G, Zangrillo A, Zanella A et al (2020) Baseline characteristics and outcomes of 1591 patients infected with SARSCoV-2 admitted to ICUs of the Lombardy Region, Italy. JAMA 323:1574-1581. https://doi.org/10.1001/jama.2020.5394

11. Age sex existing conditions of COVID-19 cases and deaths. Available at: https://www.worldometers.info/coronavirus/coron avirus-age-sex-demographics/ [Access date: 1 May 2020]

12. Brown SM, Bose S, Banner-Goodspeed V et al (2019) Approaches to addressing post-intensive care syndrome among intensive care unit survivors: a narrative review. Ann Am Thorac Soc 16:947-956. https://doi.org/10.1513/Annal sATS.201812-913FR

13. Wang S, Allen D, Kheir YN et al (2018) Aging and post-intensive care syndrome: a critical need for geriatric psychiatry. Am J Geriatr Psychiatry 26:212-221. https://doi.org/10.1016/j. jagp.2017.05.016

14. Serrano P, Kheir YNP, Wang S et al (2019) Aging and postintensive care syndrome- family: a critical need for geriatric psychiatry. Am J Geriatr Psychiatry 27:446-454. https://doi. org/10.1016/j.jagp.2018.12.002

15. Azoulay E, Vincent JL, Angus DC et al (2017) Recovery after critical illness: putting the puzzle together-a consensus of 29 . Crit Care 21:296. https://doi.org/10.1186/s13054-017-1887-7

16. Inoue $S$, Hatakeyama J, Kondo $Y$ et al (2019) Post-intensive care syndrome: its pathophysiology, prevention, and future directions. Acute Med Surg 6:233-246. https://doi.org/10.1002/ ams 2.415

17. Prescott HC, Iwashyna TJ, Blackwood B et al (2019) Understanding and enhancing sepsis survivorship. Priorities for research and practice. Am J Respir Crit Care Med 200:972-981. https://doi. org/10.1164/rccm.201812-2383CP

18. Guerra C, Hua M, Wunsch H (2015) Risk of a diagnosis of dementia for elderly medicare beneficiaries after intensive care. Anesthesiology 123:1105-1112. https://doi.org/10.1097/ALN.00000 00000000821

19. Davydow DS, Gifford JM, Desai SV et al (2008) Posttraumatic stress disorder in general intensive care unit survivors: a systematic review. Gen Hosp Psychiatry 30:421-434. https://doi. org/10.1016/j.genhosppsych.2008.05.006

20. Rabiee A, Nikayin S, Hashem MD et al (2016) depressive symptoms after critical illness: a systematic review and metaanalysis. Crit Care Med 44:1744-1753. https://doi.org/10.1097/ CCM.0000000000001811

21. Nikayin S, Rabiee A, Hashem MD et al (2016) Anxiety symptoms in survivors of critical illness: a systematic review and meta-analysis. Gen Hosp Psychiatry 43:23-29. https://doi.org/10.1016/j. genhosppsych.2016.08.005

22. Schmidt M, Azoulay E (2012) Having a loved one in the ICU: the forgotten family. Curr Opin Crit Care 18:540-547. https://doi. org/10.1097/MCC.0b013e328357f141

23. Balas MC, Burke WJ, Gannon D et al (2013) Implementing the awakening and breathing coordination, delirium monitoring/management, and early exercise/mobility bundle into everyday care: opportunities, challenges, and lessons learned for implementing the ICU pain, agitation, and delirium guidelines. Crit Care Med 41:S116-127. https://doi.org/10.1097/CCM.0b013e3182a17064 
24. Marra A, Ely EW, Pandharipande PP et al (2017) The ABCDEF bundle in critical care. Crit Care Clin 33:225-243. https://doi. org/10.1016/j.ccc.2016.12.005

25. Rawal G, Yadav S, Kumar R (2017) Post-intensive care syndrome: an overview. J Transl Int Med 5:90-92. https://doi.org/10.1515/ jtim-2016-0016
Publisher's Note Springer Nature remains neutral with regard to jurisdictional claims in published maps and institutional affiliations. 